\title{
VITAMIN B 12 AND FOLIC ACID DEFICIENCY AMONG MALNOURISHED CHILDREN WITH PANCYTOPENIA.
}

1. MBBS, FCPS

Professor Pediatric Medicine,

Sheikh Zayed Medical College,

Rahim Yar Khan.

2. M.Phil

Associate Professor

Department of Community Medicine Sheikh Zayed Medical College,

Rahim Yar Khan.

3. FCPS

Senior Registrar Pediatric Medicine

Sheikh Zayed Medical College,

Rahim Yar Khan.

4. MBBS

PGR Pediatric Medicine

Sheikh Zayed Medical College,

Rahim Yar Khan.

5. FCPS

Senior Registrar Pediatric Medicine

Sheikh Zayed Medical College,

Rahim Yar Khan.

6. FCPS

Pediatrician RHC Kot Samaba.

Correspondence Address:

Dr. Jamal Anwer

Care of Pakistan Medical Complex,

Sheikh Zayed Hospital Road, Rahim

Yar Khan

drjamalanwer2000@yahoo.com

Article received on:

11/07/2019

Accepted for publication:

27/09/2019

Jamal Anwer ${ }^{1}$, Ghulam Mustafa², Sajida Khalid ${ }^{3}$, Shoaib Younis ${ }^{4}$, Riaz ul Haq ${ }^{5}$, Hafiz Muhammad Tayyab ${ }^{6}$

ABSTRACT... Objectives: To determine Vitamin B12 and Folic Acid Deficiency among Malnourished Children with Pancytopenia. Study Design: Cross-Sectional study. Setting: Department of Pediatric Sheikh Zayed Medical College / Hospital, Rahim Yar Khan. Period: $1^{\text {st }}$ April 2017 to 25th February 2018. Material \& Methodology: In this study 60 children having malnutrition and pancytopenia were included. The given performa was filled and record was maintained. Children visiting Paediatric OPD or admitted in the ward having severe malnutrition and pancytopenia in Complete Blood Count were included in the study. While the malnourished Children with normal blood count and children with malignancy e.g; Leukemia, lymphoma etc. were excluded from the study. Results: In this study, mean age of patients was $5 \pm 4.2$ years, mean weight $10.3 \pm 7.6 \mathrm{~kg}$, mean hemoglobin was $6 \pm 6.5 \mathrm{~g} / \mathrm{dl}$, mean folic acid was $7.7 \pm 6.7$

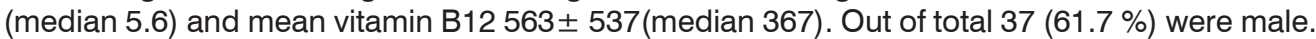
In this study, grade I malnutrition was 2 (3.3\%), grade II, $17(28.3 \%)$ and grade III, $41(68.3 \%)$. Conclusion: Vitamin B 12 \& Folic Acid deficiency is found to be a major factor of bone marrow suppression in malnourished children and our result showed that folic acid deficiency was significantly low in females and Vitamin B12 in males.

Key words: $\quad$ Folic Acid, Malnutrition, Pancytopenia, Vitamin B 12

Article Citation: Anwer J, Mustafa G, Khalid S, Younis S, Riaz ul Haq, Tayyab HM. Vitamin B 12 and Folic Acid Deficiency among Malnourished Children with Pancytopenia. Professional Med J 2020; 27(2):348-352.

DOI: 10.29309/TPMJ/2020.27.2.3937

\section{INTRODUCTION}

Malnutrition means a pathological state of relative or absolute, deficiency or excess of one or more micro or macronutrients. ${ }^{1}$ Deficiency of protein, carbohydrate or minerals lead to various types of malnutrition. Children with malnutrition suffer from poor immunity, delayed wound healing, muscle weakness and reduced psychologic drive. ${ }^{2}$ In developing countries, nutritional deficiency is always common. Worldwide around 800 million people are affected by malnutrition. According to $\mathrm{WHO}$, more than half of the childhood deaths are due to malnutrition especially in developing countries. Each year around 10.6 million children in the world die before 5 years of age. In an estimation, out of ten of these, seven deaths are due to diarrhea, pneumonia, malaria, measles or malnutrition. ${ }^{1}$ Lack of effective prevention and treatment accounts for almost all of these avoidable deaths. ${ }^{3}$ Macronutrients (protein, fats and carbohydrates) can be generated by the body itself but the source of some micronutrients is only the diet. These micronutrients are vitamins A, B complex, C, folate, zinc, calcium, iron and iodine.

Pancytopenia means the deficiency of all types of blood cells including red blood cells (RBCs), white blood cells (WBCs) and platelets. It may be central or peripheral. Aplastic anemia means the decrease in production of all types of blood cells. It is because of the dysfunction or destruction of pluripotent stem cell (progenitor of erythrocytes, platelets and granulocytes). ${ }^{4}$ Pancytopenia has multiple effects on the body in the form of hypoxemia and disturbance of immune function. The most of the cases of acquired bone marrow failure in childhood are "idiopathic". ${ }^{5}$ There are multiple studies in which micronutrients specially folic acid and vitamin B 12 are associated with pancytopenia. The blood picture of the deficiency of these two micronutrients are sometime same. 
There is often a pancytopenia with macrocytosis. ${ }^{6}$ The study we have conducted in malnourished children is to determine the relation of vitamin $B$ 12 and folic acid deficiency with pancytopenia.

\section{Material \& METHODOLOGY}

\section{Study Design}

Cross Sectional Study

\section{Sample Size}

60 malnourished children with pancytopenia.

\section{Study Subject}

All the malnourished children presenting with pancytopenia was investigated for Vitamin. B 12 and Folic Acid level in their blood and find out the relation of Pancytopenia with these micronutrients.

\section{Inclusion Criteria}

Following Children were included in the study:

- Children visiting in Paediatric OPD or admitted in the Ward

- Children visiting in private clinics

- Severely Malnourished children (grade 3 Gomez Classification)

- Pancytopenia in Complete Blood Count

\section{Exclusion Criteria}

- Malnourished Children with normal blood count

- Children with malignancy e.g; Leukemia, lymphoma etc.

\section{Data Collection Method}

The data was collected on a predesigned questionnaire with variable including age, sex, vitamin B 12 and folic acid levels in serum.

\section{Data Analysis}

SPSS version 23 was used for the analysis of collected data. Quantitative variables were age, weight of the child, degree of malnutrition, serum level of vitamin B12 and Folic acid. These variables were presented as mean and standard deviation. Qualitative variables were gender and socioeconomic status of the child. Post stratification Chi-Square was applied. $\mathrm{P}$ vale $\leq$ 0.05 was taken as significant. Ethical approval was sought from Institutional Review Board.

\section{RESULTS}

In this study, the mean age of patients was 5 \pm 4.2 years, mean weight $10.3 \pm 7.6 \mathrm{~kg}$, mean hemoglobin was $6 \pm 6.5 \mathrm{~g} / \mathrm{dl}$, mean folic acid was $7.7 \pm 6.7$ (median 5.6) and mean vitamin B12 563 \pm 537 (median 367). Out of total 37 (61.7 $\%)$ were male. In this study, grade I malnutrition was $2(3.3 \%)$, grade I I, $17(28.3 \%)$ and grade I I I, 41(68.3\%).

Table-I shows that among malnourished children with pancytopenia $27(45 \%)$ have normal serum Folic acid level, 7 (11.7\%) has excess and 26 (43.3\%) has significant deficiency and it is more in female $(P=0.00)$. Regarding Vitamin B12 level37 $(61.7 \%)$ has normal level, $12(20 \%)$ has excess, and $11(18.3 \%)$ has deficiency and it is more in males $(P=0.05)$.

\begin{tabular}{|c|c|c|c|c|c|c|}
\hline & \multicolumn{3}{|c|}{ Folic acid } & \multirow{2}{*}{ Total } & \multirow{2}{*}{ P-Value } \\
\hline & & Normal & Excess & Deficiency & & \\
\hline \multirow{2}{*}{ Sex } & Male & 21 (56.8\%) & $6(16.2 \%)$ & $10(27.0 \%)$ & 37 (100\%) & \multirow{3}{*}{0.00} \\
\hline & Female & $6(26.1 \%)$ & $1(4.3 \%)$ & $16(69.6 \%)$ & 23 (100\%) & \\
\hline \multicolumn{2}{|c|}{ Total } & 27 (45\%) & 7 (11.7\%) & $26(43.3 \%)$ & 60 (100\%) & \\
\hline & & \multicolumn{3}{|c|}{ Vitamin B12 } & \multirow{2}{*}{ Total } & \multirow{2}{*}{ P-Value } \\
\hline & & Normal & Excess & Deficiency & & \\
\hline \multirow{2}{*}{ Sex } & Male & 19 (51.4\%) & $8(21.6 \%)$ & $10(27.0 \%)$ & 37 (100\%) & \multirow{3}{*}{0.05} \\
\hline & Female & 18 (78.3\%) & 4 (17.4\%) & $1(4.3 \%)$ & 23 (100\%) & \\
\hline \multicolumn{2}{|c|}{ Total } & $37(61.7 \%)$ & $12(20 \%)$ & $11(18.3 \%)$ & $60(100 \%)$ & \\
\hline
\end{tabular}

Table-I. Sex distribution versus Folic Acid and vitamin B 12 in malnourished children with pancytopenia. 


\section{DISCUSSION}

In malnourished children, there are different factors leading to bone marrow suppression. Iron deficiency anemia leads to microcytic, hypocromic anemia. Other vitamins and minerals can also cause anemia. Folic acid and Vitamin $B_{12}$ are essential components in DNA synthesis. Folic acid is directly involved while Vitamin $B_{12}$ participates as a co-factor. A deficiency of Vitamin $B_{12}$ causes the same symptoms as folic acid deficiency. Deficiency of either factor disrupts the maturation process of cells which leads to megaloblastic change in precursors. Ifra Sameen, Yasmin Chana described that Pancytopenia due to Folic Acid and Vitamin B 12 deficiency is more common in malnourished children. ${ }^{7}$ Sarode R, Garewal $G$ et al found that during progression (in terms of duration) of megaloblastosis, anemia is followed by thrombocytopenia and then neutropenia. ${ }^{8}$ Gomber S, Kumar $S$ et al found that isolated deficiency of Vitamin B12 or in combination with iron deficiency, is an important cause of anemia. Same is with Folic acid deficiency. ${ }^{9}$

Talarmin F, Hugard L et al recognized that vitamin B12 and Folic acid deficiencies are common in underdeveloped countries and are responsible of megaloblastic anemia and pancytopenia. ${ }^{10}$ Sarode R1, Garewal G et al found that out of 139 patients of pancytopenia, 102 cases in whom the biochemical parameters were available, vitamin B12 deficiency was detected in $76 \%$, folate deficiency in $6.8 \%$, combined B12 and folate deficiency in $8.8 \%$; the remaining $7.8 \%$ had normal vitamin levels at presentation. ${ }^{11}$ Palaniyandi Anitha, Rajendraprasad Sasitharan et al reported Helicobacter pylori $(\mathrm{H}$. pylori) related B12 deficiency presenting as pancytopenia in pediatric age groups. ${ }^{12}$

Hansen PB, Jorgensen LM found that the patients suffering from pancytopenia of folic acid deficiency were improved after the administration of folic acid. ${ }^{13}$ Osman Yokus, Ozlem Sahin Balcik described a patient who admitted with walking difficulties for 15 days the investigations showed pancytopenia and elevated LDH. His condition was improved after treatment with folic acid and vit B12. ${ }^{14}$ Ozlem Pelin Simşek, Nazli Gönç et al described a 16-month-old infant who presented with developmental regression, pancytopenia, skin pigmentation and tremor resulting from vitamin B12 deficiency. ${ }^{15} 109$ pediatric patients with pancytopenia were analyzed by Shishir Kumar Bhatnagar, Jagdish Chandra et al retrospectively and megaloblastic anemia was found to be the most common etiological factor(28.4 per cent). ${ }^{16}$ Sushant Mane, Sonali singh et al intramuscular methylcobalamine for 2 weeks followed by oral methylcobalamine and folic acid. ${ }^{17}$ Enver Atay, Mehmet Akin found decreased count in different cell lines in some patients out of $212 .{ }^{18}$ During finding the frequency of the different causes of Pancytopenia, Tariq Aziz, Liaquat Ali et al observed pancytopenia in a large number $(40.90 \%)$ of patients who were diagnosed as Megaloblastic Anemia. Out of them, $77.77 \%$ had vitamin B12 deficiency. ${ }^{19}$

Ravindra Sarode, G Garewal et al concluded that during progression (in terms of duration) of megaloblastosis, anemia is followed by thrombocytopenia and then neutropenia. ${ }^{20}$ Salma Haq, Nasir lqbal et al found that Folic acid deficiency $(62.5 \%)$ was the commonest cause of megaloblastic anemia. ${ }^{21}$ This study revealed that almost half of children having malnutrition and pancytopenia has folic acid deficiency and it was more in female $(P=0.00)$, whereas one fifth of these children has vitamin B12 deficiency and more in male $(P=0.05)$. In contrast to our study, some of the previous studies have described that deficiency of Vitamin B12 was more common than folic acid deficiency in patients with severe acute malnutrition. ${ }^{22,23}$

\section{CONCLUSION}

Vitamin B 12 and Folic Acid deficiency may be a major factor of bone marrow suppression in malnourished children and our result showed that folic acid deficiency was significantly low in females and Vitamin B12 in males.

Copyright@ 29 Sep, 2019. 


\section{REFERENCES}

1. Pervez Akbar Khan "Pediatric nutrition and nutritional disorders: Malnutrition" Basis of Pediatrcs, $8^{\text {th }}$ Edition P 97- 100 .

2. Raanan Shamir, David Branski "Chronic malnutrition" Nelson text book of Pediatrics 19th Edition, P: 1844 1845.

3. Barbara Golden, John Reilly "Nutrition" Forfar and Arneil's, Textbook of Pediatrics, 7th edition. P 523-526.

4. Pervez Akbar Khan "Hematologic disorders" Basis of Pediatrcs, $8^{\text {th }}$ Edition P 449- 450.

5. Jeffery D. Hord, "The acquired pancytopenias" Nelson text book of Pediatrics 19th Edition, P: 2370 - 2372.

6. Paula Bolton- Maggs, Angela Thomas "Disorders of the blood and bone marrow" Forfar and Arneil's Textbook of Pediatrics, 7th edition. P 964.

7. Ifra Sameen, Yasmin Chana "Study of Vitamin B 12 and folate level in children with Pancytopenia". Pak Pediatr J 2015; 39 (2): 73 - 79.

8. Sarode R, Garewal $\mathrm{G}$ et al, "Pancytopenia in nutritional megaloblastic anemia. A study from north-west India". Trop Geogr Med. 1989 Oct; 41(4):331-6.

9. Gomber S, Kumar S, "Prevalence \& etiology of nutritional anemias in early childhood in an urban slum”. Indian J Med Res. 1998 Jun; 107:269-73.

10. Talarmin F1, Hugard Let al, "Vitamin deficiency pancytopenia" Ann Med Interne (Paris). 1994; 145(3):159-62.

11. Sarode R1, Garewal G, Marwaha N. Pancytopenia in nutritional megaloblastic anaemia. A study from north-west India. Indian J Med Res. 1998 Jun; 107:26973.

12. Palaniyandi Anitha, Rajendraprasad Sasitharan et al. Vitamin B12 deficiency presenting as pancytopenia and retinopathy in a young boy-Helicobacter pylori, a novel causative agent. Australas Med J. 2014; 7(3): 143-148.

13. Hansen PB, Jørgensen LM. Pancytopenia--a rare manifestation of folic acid deficiency. J Intern Med. 1989 Feb; 225(2):143-4.
14. Osman Yokus, Ozlem Sahin Balcik. Megaloblastic anemia patient admitted with pancytopenia and walking difficulty with normal vitamin B12 and MCV levels. Pakistan Journal of Medical Sciences. July 2010, 26 (3):736-739.

15. Ozlem Pelin Simşek, Nazli Gönç, Fatma Gümrük. A child with vitamin B12 deficiency presenting with pancytopenia and hyperpigmentation. Journal of Pediatric Hematology/Oncology, January 2005, 26 (12):834-6.

16. Shishir Kumar Bhatnagar, Jagdish Chandra, Shashi Narayan, Sunita Sharma. Pancytopenia in children: Etiological Profile Journal of Tropical Pediatrics 51, No. (40): 236-239.

17. Sushant Mane, Sonali Singh, Swapnil Kumar. Bleeding diathesis: When do we suspect vitamin B12 deficiency? JMSCR March 2016, 4 (3) 9761- 64.

18. Enver Atay, Mehmet Akin, Bayram Ozhan, Oztekin Osman. Frequency of hematological findings associated with severe plasma vitamin B12 deficiency in Infants and Adolescents. Clinical laboratory April 2014. 60(4):659-62.

19. Tariq Aziz, Liaquat Ali, Tahir Ansari. Pancytopenia: Megaloblastic anemia is still the commonest cause. Pakistan Journal of Medical Sciences Online. January 2010. 2626(1):132-6.

20. Ravindra Sarode, G Garewal, Neelam Marwaha, R K Marwaha. Pancytopenia in nutritional megaloblastic anaemia. A study from North-West India Tropical and geographical medicine November 1989. 41(4):331-6.

21. Salma Haq, Nasir Iqbal, Fatima Fayyaz, Tahira Tasneem. Serum B12 and folate levels in patients with megaloblastic change in the bone marrow. Biomedica (jan. - jun. 2012) vol. 28

22. Yaikhomba, T., Poswal, L, Goyal, S. Assessment of iron, folate and vitamin B12 in patients with severe acute malnutrition. Indian J Pediatr (2015) 82: 511. https://doi.org/10.1007/s12098-014-1600-7

23. Goyal S, Tiwari K, Meena P, Malvia S. Cobalamin and folate status in malnourished children. Inter $\mathrm{J}$ Contem Peads 2017; 4. 1480. DOI: 10.18203/2349-3291. ijcp20172690. 


\begin{tabular}{|c|l|l|l|}
\hline \multicolumn{3}{|c}{ AUTHORSHIP AND CONTRIBUTION DECLARATION } \\
\hline Sr. \# & \multicolumn{1}{|c|}{ Author(s) Full Name } & \multicolumn{1}{|c|}{ Contribution to the paper } & Author(s) Signature \\
\hline 1 & Jamal Anwer & $\begin{array}{l}\text { Idea Generation, Data } \\
\text { analysis. } \\
\text { Data analysis. }\end{array}$ \\
\hline 2 & Ghulam Mustafa & $\begin{array}{l}\text { Data collection, Literature } \\
\text { review. } \\
\text { Data collection. }\end{array}$ \\
\hline 4 & Sajida Khalid & Shoaib Younis & Literature review. \\
\hline 5 & Riaz ul Haq & Hafiz Muhammad Tayyab & Data collection. \\
\hline
\end{tabular}

